\title{
Correction to: Anteroposterior and vertical soft tissue cephalometric norms of Iranians, interethnic comparisons, sex dimorphism, and the effect of age on cephalometric variables
}

Vahid Rakhshan $^{1} \cdot$ Fataneh Ghorbanyjavadpour ${ }^{2}$

Published online: 2 May 2019

(C) Springer-Verlag GmbH Germany, part of Springer Nature 2019

\section{Correction to: Oral and Maxillofacial Surgery}

https://doi.org/10.1007/s10006-019-00755-4

In page 8 , column 2, lines 9-10: the words "males" and "females" are written in reverse order.

The correct text should be:

Compared to females, Iranian males had taller upper lips, taller lower thirds compared to middle thirds, taller chins (lips closer to the nose), taller faces (longer distances between lips and both the chin and subnasale), deeper superior and inferior sulci, more retruded lower lips and chins, thicker upper lips, and thicker chins.

Publisher's note Springer Nature remains neutral with regard to jurisdictional claims in published maps and institutional affiliations.

The online version of the original article can be found at https://doi.org/ 10.1007/s10006-019-00755-4

Fataneh Ghorbanyjavadpour

fa.ghorbanyjavad@gmail.com

1 Department of Dental Anatomy, Dental Faculty, Azad University, Tehran, Iran

2 Orthodontics Department, School of Dentistry, Ahvaz Jundishapur University of Medical Sciences, Ahvaz, Iran 